\title{
Critical state of energy metabolism in brain slices: the principal role of oxygen delivery and energy substrates in shaping neuronal activity
}

\author{
Anton Ivanov and Yuri Zilberter * \\ INSERM UMR751, Université de la Méditerranée, Marseille, France
}

\section{Edited by:}

Sebastian Cerdan, Instituto de Investigaciones Biomedicas Alberto Sols, Spain

\section{Reviewed by:}

Sebastian Cerdan, Instituto de Investigaciones Biomedicas Alberto Sols, Spain

Elizabeth Hillman, Columbia

University, USA

Juan C. Saez, Universidad Catolica de Chile, Chile

\section{*Correspondence:}

Yuri Zilberter, Faculté de Médecine Timone, INSERM U751, 27 Bd Jean Moulin, 13385 Marseille Cedex 05

France.

e-mail:yuri.zilberter@univmed.fr

\begin{abstract}
The interactive vasculo-neuro-glial system controlling energy supply in the brain is absent in vitro where energy provision is determined by experimental conditions. Despite the fact that neuronal activity is extremely energy demanding, little has been reported on the state of energy metabolism in submerged brain slices. Without this information, the arbitrarily chosen oxygenation and metabolic provisions make questionable the efficient oxidative metabolism in slices. We show that in mouse hippocampal slices (postnatal day 19-44), evoked neuronal discharges, spontaneous network activity (initiated by 4-aminopyridine), and synaptic stimulation-induced $\mathrm{NAD}(\mathrm{P}) \mathrm{H}$ autofluorescence depend strongly on the oxygen availability. Only the rate of perfusion as high as $\sim 15 \mathrm{ml} / \mathrm{min}\left(95 \% \mathrm{O}_{2}\right)$ provided appropriate oxygenation of a slice. Lower oxygenation resulted in the decrease of both local field potentials and spontaneous network activity as well as in significant modulation of short-term synaptic plasticity. The reduced oxygen supply considerably inhibited the oxidation phase of $\mathrm{NAD}(\mathrm{P}) \mathrm{H}$ signaling indicating that the changes in neuronal activity were paralleled by the decrease in aerobic energy metabolism. Interestingly, the dependence of neuronal activity on oxygen tension was clearly shifted toward considerably larger $\mathrm{pO}_{2}$ values in slices when compared to in vivo conditions. With sufficient $\mathrm{pO}_{2}$ provided by a high perfusion rate, partial substitution of glucose in ACSF for $\beta$-hydroxybutyrate, pyruvate, or lactate enhanced both oxidative metabolism and synaptic function. This suggests that the high $\mathrm{pO}_{2}$ in brain slices is compulsory for maintaining oxidative metabolism, and glucose alone is not sufficient in fulfilling energy requirements during neuronal activity. Altogether, our results demonstrate that energy metabolism determines the functional state of neuronal network, highlighting the need for the adequate metabolic support to be insured in the in vitro experiments.
\end{abstract}

Keywords: energy substrates, brain slices, synaptic plasticity, neuronal activity, energy metabolism, oxygen, $\mathrm{NAD}(\mathrm{P}) \mathrm{H}$, local field potential

\section{INTRODUCTION}

In the intact brain, complex machinery exists that coordinates energy substrates delivery and adjusts energy substrate pool composition to the needs of neuronal energy metabolism (Abbott et al., 2010; Pellerin, 2010; Turner and Adamson, 2011). In the acute brain slices, such a sophisticated system does not exist and the neuronal energy supply depends entirely on the experimental conditions. The primary requirement for the in vitro studies is to provide experimental conditions, which would approximate as close as possible the in vivo situation. One parameter of critical importance is the adequate slice oxygenation compulsory for aerobic energy metabolism.

For instance, it has been demonstrated that neuronal synaptic function (Yamamoto and Kurokawa, 1970; Garcia et al., 2010; Ivanov et al., 2011), networks' ability to generate physiologicallike oscillations (Huchzermeyer et al., 2008; Hajos et al., 2009; Kann et al., 2011), and efficiency of glucose utilization for supporting neuronal activity (Schurr and Payne, 2007) all strongly depend on the oxygen tension in slices. In the few available electrophysiological studies with direct measurements of slice tissue oxygenation, a strong dependence of neuronal functions on oxygen was observed in the range of $\mathrm{pO}_{2}(100-400$ Torr; Foster et al., 2005; Hajos et al., 2009; Garcia et al., 2010; Ivanov et al., 2011; Kann et al., 2011) that exceeded the physiological $\mathrm{pO}_{2}$ range (10-60 Torr) in brain tissue in vivo (Erecinska and Silver, 2001; Masamoto et al., 2003, 2007; Takano et al., 2007). This fact suggests that the oxygen requirement for neuronal function is much higher in slices than in vivo. In the majority of electrophysiological studies performed on submerged slices, the oxygen tension in tissue was not controlled while the solution flow rate (normally $2-4 \mathrm{ml} / \mathrm{min}$ ) or chamber constructions were chosen from the assumptions not substantiated by the direct measurements. The adequacy of such approach may be especially questionable for the interpretation of multicellular activity measurements related to the functioning of neurons throughout the slice depth (Hajos and Mody, 2009). 
Another important issue is the composition of energy substrate pool in ACSF. Standard ACSF contains glucose as the only energy substrate. Historically, the composition of ACSF was developed for replacement of physiological fluids in clinics (see for review Zilberter et al., 2010) but not for mimicking the extracellular neuron environment. Glucose indeed is the main energy substrate in blood circulating in the adult brain. However, the composition of energy substrate pool in the brain extracellular fluid may be complex and is defined by several factors such as network activity, neuron-glia interactions, substrate delivery across the blood brain barrier, and others. For instance, it has been recently demonstrated that lactate is the preferable neuronal fuel during the intense brain activity (Wyss et al., 2011). In slices, it is unclear whether glucose itself is able to fully cover energy demands during network activity. We have shown recently in neonatal slices that supplementing glucose in ACSF with other oxidative energy substrates enhances both the aerobic metabolism and synaptic function (Ivanov et al., 2011). These results suggest that the sole use of glucose in ACSF may not be optimal in mature slices as well. In addition, it has been demonstrated (Whittingham et al., 1984; Zur Nedden et al., 2011) that the levels of adenine nucleotides in slices is about 50\% lower than those measured in vivo, indicating that some processes underlying neuronal energy metabolism may be disrupted.

Therefore, the critical question is how close the experimental conditions accepted for the electrophysiological studies on slices approximate the natural neuronal environment in the brain and thus with what confidence the data obtained in these experiments extrapolate to the real in vivo situation.

In our previous study on neonatal brain slices (Ivanov et al., 2011) we demonstrated the importance of oxidative metabolism of glucose-alternative energy substrates for the neuronal function. In the present study, we show that this conclusion is not limited to neonates but is valid for mature animals as well. In addition, we examine the influence of oxygen tension on neuronal population/spontaneous activity, our data pointing to a much stronger dependence of neuronal activity on oxygen tension in slices than that seen in vivo.

\section{MATERIALS AND METHODS TISSUE SLICE PREPARATION}

Brain slices were prepared from P19 to P44 Swiss mice of both sexes. All animal protocols conformed to the French Public Health Service policy and the INSERM guidelines on the use of laboratory animals. The mouse was rapidly decapitated and the brain was removed from the skull and placed in the ice-cold ACSF oxygenated with $95 \% \mathrm{O}_{2} / 5 \% \mathrm{CO}_{2}$. The ACSF solution consisted of (in $\mathrm{mM} / \mathrm{l}): \mathrm{NaCl} 124, \mathrm{KCl} 2.50, \mathrm{NaH}_{2} \mathrm{PO}_{4} 1.25, \mathrm{NaHCO}_{3} 25, \mathrm{CaCl}_{2}$ 2.00, $\mathrm{MgCl}_{2}$ 1.30, and dextrose $10, \mathrm{pH} 7.4$. Sagittal slices $(350 \mu \mathrm{m})$ were cut using a tissue slicer (Leica VT 1200 s, Leica Microsystem Vertrieb GmbH, Germany). During cutting slices were submerged in an ice-cold $\left(<6^{\circ} \mathrm{C}\right)$ cutting solution consisted of (in $\mathrm{mM} / \mathrm{l}$ ): K-gluconate 140, HEPES 10, Na-gluconate 15, EGTA 0.2, $\mathrm{NaCl} 4$, $\mathrm{pH}$ adjusted to 7.2 with $\mathrm{KOH}$. Slices were transferred immediately to a multi-well, dual-sided perfusion holding camera with constantly circulating oxygenated $\left(95 \% \mathrm{O}_{2} / 5 \% \mathrm{CO}_{2}\right)$ ACSF maintained at room temperature $\left(22-24^{\circ} \mathrm{C}\right)$, and allowed to recover for $2 \mathrm{~h}$. The chamber was designed for minimizing the $\mathrm{O}_{2}$ escape and providing rapid solution exchange during incubation (whole volume renewal time $<3 \mathrm{~min}$ ). Slices were then transferred to a recording chamber continuously superfused and oxygenated with $95 \% \mathrm{O}_{2} / 5 \% \mathrm{CO}_{2}\left(33-34^{\circ} \mathrm{C}\right)$.

\section{SYNAPTIC STIMULATION AND FIELD POTENTIAL RECORDINGS}

Shaffer collateral/commissural pathway was stimulated using the DS2A isolated stimulator (Digitimer Ltd., UK) with a bipolar nichrome electrode situated in the stratum radiatum (SR) of CA1 hippocampal region. Stimulus current was adjusted using single pulses $(170-240 \mu \mathrm{A}, 200 \mu \mathrm{s}, 0.15 \mathrm{~Hz})$ to produce a local field potential (LFP) of nearly $50 \%$ of maximal amplitude. LFPs were recorded using glass microelectrodes filled with ASCF, placed in stratum pyramidale at the $100-$ to $150-\mu \mathrm{m}$ depth and connected to the DAM-80 amplifier (WPI, FL, USA). Synaptic stimulation consisted of a 30 -s stimulus train $(200 \mu$ s pulses at $10 \mathrm{~Hz}$ ) was used to generate autofluorescence reduced pyridine nucleotide $(\mathrm{NAD}(\mathrm{P}) \mathrm{H})$ response. LFPs were quantified by calculating their integral as described elsewhere (Ivanov et al., 2011). Field postsynaptic potentials (fPSPs) were calculated by subtracting population spikes from LFPs.

\section{NAD(P)H FLUORESCENCE IMAGING}

Reduced nicotinamide adenine dinucleotide phosphate (NADPH) and reduced nicotinamide adenine dinucleotide (NADH) have very similar optical properties, and therefore is expected that NADPH also contributes to some extent to total autofluorescence signals (Klaidman et al., 1995; Shuttleworth, 2010). Moreover, recent reports suggest the importance of pentose-phosphate pathway for neuronal glucose metabolism (Bolanos et al., 2010). Changes in $\mathrm{NAD}(\mathrm{P}) \mathrm{H}$ fluorescence in hippocampal slices were monitored using a 290- to 370-nm excitation filter and $420 \mathrm{~nm}$ long pass filter for emission (Omega Optical, Brattleboro, VT, USA). The light source was the Intensiligh C-HGFI illuminator (Nikon Instruments Europe B.V., UK) equipped with a mercury arc lamp. Slices were epi illuminated and imaged through a Nikon upright microscope (FN1, Eclipse) with $4 \times / 0.10$ Nikon Plan objective. Images were acquired using a linear, cooled 12-b CCD camera (Sensicam, PCO AG, Germany) with a $640 \times 480$ digital spatial resolution. Because of a low level of fluorescence emission for this fluorophore, $\mathrm{NAD}(\mathrm{P}) \mathrm{H}$ images were acquired every $600-800 \mathrm{~ms}$ as $8 \times 8$ binned images (effective spatial resolution of $80 \times 60$ pixels). The exposure time was adjusted to obtain fluorescence intensity between 2000 and 3000 optical intensity levels. Images were stored in a computer as 12-b files (0-4096 dynamic range). Fluorescence intensity changes in SR near sites of LFP and $\mathrm{pO}_{2}$ recordings were extracted in three to five regions of interest using ImageJ software (developed by Wayne Rasband, $\mathrm{NIH}$, USA). Data were expressed as the percentage changes in fluorescence over a baseline $[(\Delta F / F) \cdot 100 \%]$. Signal analysis was performed using IgorPro software (WaveMetrics, Inc., OR, USA).

\section{OXYGEN MEASUREMENTS}

A Clark-style oxygen microelectrode (OX-10, tip diameter $10 \mu \mathrm{m}$; Unisense Ltd., Denmark) was used to measure slice tissue $\mathrm{PO}_{2}$. The electrode was connected to a picoammeter (PA2000, Unisense Ltd., Denmark) and the cathode was polarized at $-800 \mathrm{mV}$ in 
normal saline at $22^{\circ} \mathrm{C}$ for up to $12 \mathrm{~h}$ before the first use. A twopoint calibration (in $\mathrm{pA}$ ) was performed following polarization by inserting the electrode in normal saline solution $\left(\right.$ at $33^{\circ} \mathrm{C}$ ) equilibrated with either $95 \% \mathrm{O}_{2}-5 \% \mathrm{CO}_{2}$ or ambient air. Calibrations were repeated after each experiment to determine the $\mathrm{PO}_{2}$ values. The oxygen electrode (response time 1-3 s) was positioned using motorized micromanipulator (Scientifica Ltd., UK) in SR at the proximity to field potential recording electrode (at 100-150 $\mu \mathrm{M}$ slice depth).

\section{PHARMACOLOGY}

Drugs used were purchased from Sigma (racemic mixture of DL3-hydroxybutyric acid sodium salt, L-lactate sodium salt, pyruvate sodium salt). Within the racemic mixture, $\mathrm{D}-\mathrm{BHB}$ is the primary mediator of the physiological effects of DL-BHB, and is the only form that can function as a substrate for mitochondrial $\mathrm{BHB}$ dehydrogenase. Consequently, only $50 \%$ of exogenous DL-BHB is expected to be utilized (Tsai et al., 2006).

\section{STATISTICAL ANALYSIS}

Group measures were expressed as means \pm SEM; error bars also indicate SEM. Statistical significance was assessed using the Wilcoxon's signed paired test or Student's paired $t$-test. The level of significance was set at $p<0.05$.

\section{RESULTS OXYGEN TENSION DEPTH PROFILE IN SUBMERGED SLICES DEPENDS ON THE SOLUTION FLOW RATE}

To evaluate the oxygen availability at different slice depths we measured the oxygen tension in submerged slices placed in a standard round chamber (bottom diameter $17 \mathrm{~mm}$, volume $<1.5 \mathrm{ml}$ ) and superfused with solution from the upper side. Figure 1Aa shows the oxygen depth profile measured at 15 and $4 \mathrm{ml} / \mathrm{min}$ solution flow rates (slice is depicted by the gray color bar). Similar to our measurements on neonatal slices (Ivanov et al., 2011), $\mathrm{pO}_{2}$ began to decrease close $(200-300 \mu \mathrm{m})$ to the slice surface. Importantly, on the slice surface, $\mathrm{pO}_{2}$ was already significantly lower than that in the incoming solution ( $\sim 720$ Torr) being $441 \pm 11$ Torr at $15 \mathrm{ml} / \mathrm{min}$ and $258 \pm 53$ Torr at $4 \mathrm{ml} / \mathrm{min}(n=5)$. Note that the solution outflow was located in the vicinity of slice surface since at more distant input locations the oxygen distribution was significantly worse. At $4 \mathrm{ml} / \mathrm{min}, \mathrm{pO}_{2}$ steeply decreased within the slice depth coming close to zero at $\sim 200 \mu \mathrm{m}$. The oxygen depth profile was much better at $15 \mathrm{ml} / \mathrm{min}$ with $\mathrm{pO}_{2}$ of about 300 Torr in the slice core.

Oxygen consumption by a quiescent brain slice may be evaluated from our measurements of $\mathrm{pO}_{2}$ at variable distance from the slice surface (Figure 1). Above $400 \mu \mathrm{m}$ from the surface, $\mathrm{pO}_{2}$ remains constant $(\sim 700$ Torr $)$. Proximal to the slice, $\mathrm{pO}_{2}$ declines rapidly to about 440 Torr at the slice surface (at $15 \mathrm{ml} / \mathrm{min}$ flow rate). Therefore, we consider that the slice consumes $\mathrm{O}_{2}$ from the volume defined as the slice surface $\left(\sim 0.6 \mathrm{~cm}^{2}\right)$ multiplied by $400 \mu \mathrm{m}$. Note that in the absence of the slice, oxygen is distributed homogeneously and its concentration is $850 \mu \mathrm{M} / 1$ as calculated from the $\mathrm{pO}_{2}$ of 700 Torr, temperature $33^{\circ} \mathrm{C}$, and ACSF salinity $12 \%$. The total amount of $\mathrm{O}_{2}$ in this volume is $0.02 \mu \mathrm{M}$. The amount of $\mathrm{O}_{2}$ with the slice present can be obtained by the integration of $\mathrm{O}_{2}$ distribution over this volume, which results in a value of $0.017 \mu \mathrm{M}$. Thus, the slice consumes $0.003 \mu \mathrm{M}$ of oxygen from the perfusion chamber volume. Since the chamber volume is $1.5 \mathrm{ml}$ and ACSF is completely renewed 10 times per minute (at $15 \mathrm{ml} / \mathrm{min}$ flow rate), the $\mathrm{O}_{2}$ consumption is $0.003 \times 10=0.03 \mu \mathrm{M} / \mathrm{min}$. The mean wet weight of a $350-\mu \mathrm{m}$ thick brain slice from a P30 mouse is about $20 \mathrm{mg}$. Assuming that the oxygen utilization is constant over the slice, the oxygen consumption is $1.5 \mu \mathrm{M} / \mathrm{min} / \mathrm{g}$ of wet weight. However, it is necessary to take into account the extent of slice tissue integrity. Indeed, due to the cutting procedure, the slice edges contain mainly dead cells and the thickness of these edges has been estimated to be 35-50 $\mu \mathrm{m}$ from each side (Feig and Lipton, 1990; Frenguelli et al., 2003). Therefore, the slice volume consuming oxygen should be decreased by at least $20 \%$ (at $35 \mu \mathrm{m}$ dead edges) and that in turn increases the estimate of $\mathrm{O}_{2}$ consumption to $1.8 \mu \mathrm{M} / \mathrm{min} / \mathrm{g}$ wet weight. The reported whole brain oxygen consumption of rats is 3.4-4.6 $\mu \mathrm{M} / \mathrm{min} / \mathrm{g}$ wet weight (Erecinska and Silver, 2001). Therefore, even when exposed to a relatively high oxygen tension (440 Torr at the surface and 320 Torr in the core, blue curve in Figure 1Aa), neuronal tissue in a "quiescent" slice consumes lesser or comparable amount of oxygen to recorded consumption in vivo.

In the same experiments, to examine the effect of perfusion rate on neuronal electrical activity we also measured the LFPs in CA1 region induced by single stimulation of Schaffer collaterals (SC). In line with previous observations (Garcia et al., 2010; Ivanov et al., 2011), LFPs were strongly dependent on the perfusion rate (Figure 1Ab) with LFP integrals $53 \pm 11 \%$ smaller at $4 \mathrm{ml} / \mathrm{min}$ compared to those recorded at $15 \mathrm{ml} / \mathrm{min}$ rate (Figure 1Ac; $n=5$, $p<0.05)$.

In some previous studies, scientists used the dual laminar flow slice perfusion chambers to provide better conditions for slice functioning (Hajos and Mody, 2009). We examined whether at different rates of solution flow such configuration can significantly improve slice oxygenation and electrical activity (Figure 1B). Indeed, dual laminar flow (chamber volume $<1 \mathrm{ml}$ ) considerably enhances oxygenation of deep slice layers at low perfusion rates (Figure 1B, left) improving, therefore, the endurance of neurons in these layers. Nevertheless, at $4 \mathrm{ml} / \mathrm{min}$ perfusion rate, such an improvement in oxygenation did not appear to be sufficient enough to augment the synaptic function, as LFPs were still much smaller (by $45 \pm 16 \% ; n=7, p<0.01$ ) at $4 \mathrm{ml} / \mathrm{min}$ than those at $15 \mathrm{ml} / \mathrm{min}$ (Figure 1B, right).

Another approach sometimes utilized for improving slice oxygenation is an exchange of air directly in contact with the bath solution to oxygen. In three experiments (data not shown), such approach did not change significantly neither the slice oxygen levels nor LFP values (LFPs were by $41 \pm 17 \%$ smaller at $4 \mathrm{ml} / \mathrm{min}$ than at $15 \mathrm{ml} / \mathrm{min}$ ).

To rule out a possibility that the high perfusion rate may result in a washout of some active substances from slice tissue and thus affect LFPs, we measured LFPs at the same $15 \mathrm{ml} / \mathrm{min}$ superfusion with $95 \% \mathrm{O}_{2}$ and $\sim 50 \% \mathrm{O}_{2}$ oxygenation, partially substituting oxygen for air $(n=3)$. Similar to the experiments with different solution flow rates, lower solution oxygenation resulted in a strong reduction of LFPs (not shown). 

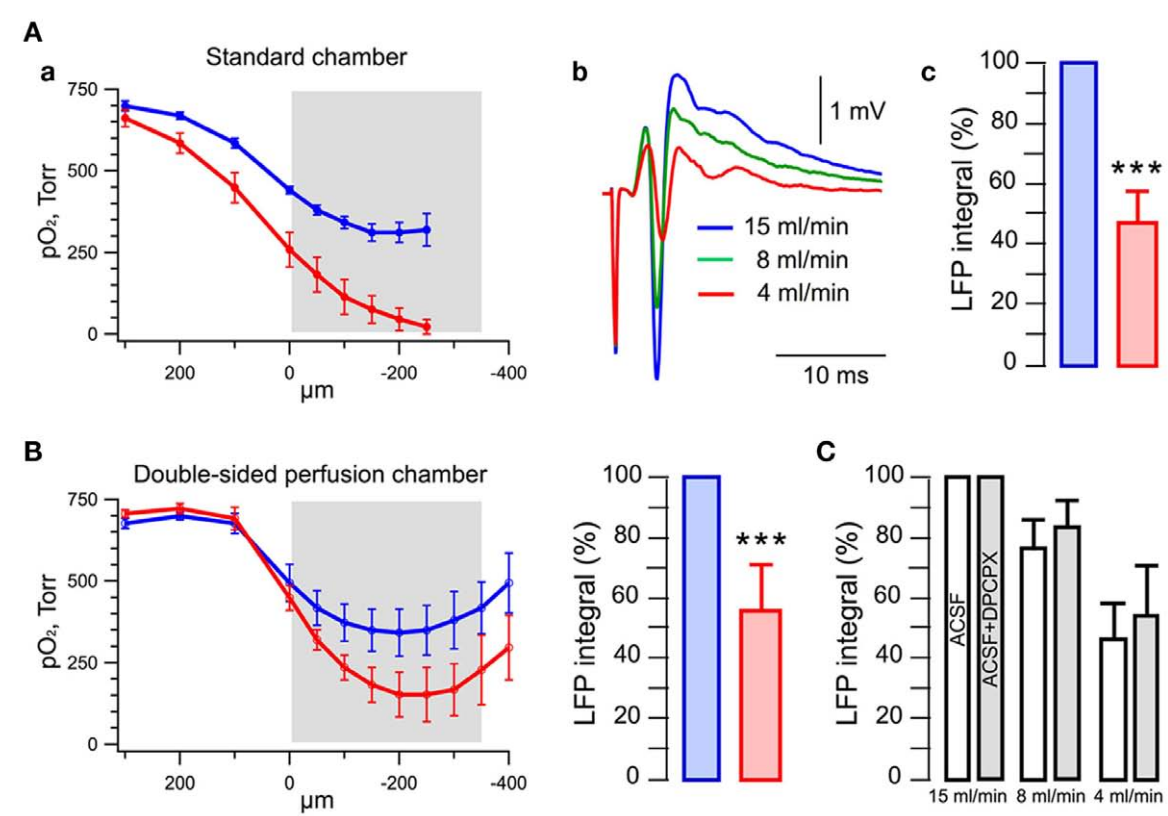

FIGURE 1 | Rate of perfusion determines oxygen distribution and LFP magnitude in a slice. (A) Measurements in a standard round chamber ( $1.5 \mathrm{ml}$ volume) with a submerged slice. (a) Oxygen depth profile at $15 \mathrm{ml} / \mathrm{min}$ (blue) and $4 \mathrm{ml} / \mathrm{min}$ (red) perfusion rate. A slice is depicted in gray; (b) LFPs recorded in CA1 in response to

$0.15 \mathrm{~Hz}$ stimulation of SC; (c) statistical summary of LFP integrals. (B) Oxygen depth profile in a custom chamber ( $<1 \mathrm{ml}$ volume) with a dual-sided perfusion of submerged slice. (C) Blockade of adenosine receptors by DPCPX does not prevent reduction of LFPs following decrease in the perfusion rate.

Finally, inhibition of neuronal energy metabolism may result in an increase in extracellular adenosine concentration, activation of the A1 type adenosine receptors and suppression of synaptic function (Zhao et al., 1997; Coelho et al., 2000). Therefore, we performed experiments with different perfusion rates in the presence of $100 \mathrm{nM}$ DPCPX, an antagonist of A1 receptors (Figure 1C). Blockade of adenosine receptors did not prevent the decrease of LFPs at lower perfusion rates and this effect did not differ significantly from that seen in ACSF: at $8 \mathrm{ml} / \mathrm{min}$, LFPs decreased by $24 \pm 9 \%$ in ACSF vs. $17 \pm 9 \%$ in ACSF $+\operatorname{DPCPX}(n=5, p=0.16)$; at $4 \mathrm{ml} / \mathrm{min}$, LFPs decreased by $55 \pm 11 \%$ in ACSF vs. $47 \pm 17 \%$ in $\mathrm{ACSF}+\operatorname{DPCPX}(n=5, p=0.27)$.

Therefore, our results indicate that at low perfusion rates, the decrease in slice oxygen tension underlies the decline of synaptic function. In addition we found no alternatives to a high rate of perfusion for maintaining sufficient oxygenation in submerged slices.

\section{OXYGEN AVAILABILITY CONTROLS ENERGY METABOLISM AND SYNAPTIC FUNCTION OF NEURONS IN SLICES}

Figure 2A demonstrates the typical recordings of LFPs and oxygen pressure during a stimulation protocol that we have used for analyzing energy metabolism and electrophysiological characteristics at prolonged neuronal population activity. Following a series of single SC stimulations (1/7 s), neurons were activated by a $30-\mathrm{s}, 10 \mathrm{~Hz}$ train $(15 \mathrm{ml} / \mathrm{min}$ perfusion rate in Figure 2$)$. The train stimulation-induced potent oxygen consumption by hippocampal cells (Figure 2A, blue) as indicated by a fast decrease in $\mathrm{pO}_{2}$ by 120 Torr during first $10 \mathrm{~s}$ of stimulation (mean rate was $200 \pm 40$ Torr per $10 \mathrm{~s}, n=7)$. LFPs in the train initially increased, presumably due to synaptic facilitation (Pitler and Landfield, 1987), but then declined strongly toward the end of train in parallel with a drop of oxygen level (by about 130 Torr). Interestingly, a slow recovery of LFPs started with a delay of about $30 \mathrm{~s}$ after the train and followed closely the $\mathrm{pO}_{2}$ recovery (Figure 2B).

We examined the energy metabolism parameters and electrophysiological characteristics of neuronal population activity at the perfusion rate of $15 \mathrm{ml} / \mathrm{min}$ and following its reduction to $4 \mathrm{ml} / \mathrm{min}$ (Figure 3). Note that in this and other experiments, the presynaptic fiber volley component of LFPs did not change whatsoever, indicating that $\mathrm{SC}$ stimulation activated a constant number of nerve fibers throughout the experiment. At high perfusion rates, the stimulation train induced a strong oxygen consumption by hippocampal cells (Figure 3A, blue) and NAD $(\mathrm{P}) \mathrm{H}$ autofluorescence revealed a biphasic transient characteristic for slices (Foster et al., 2006) with the pronounced dip (oxidation phase) and overshoot reflecting $\mathrm{NAD}(\mathrm{P})^{+}$reduction. Slowing down the rate of perfusion resulted in a considerable decrease of both oxygen consumption and $\mathrm{NAD}(\mathrm{P}) \mathrm{H}$ oxidation phase (Figure 3A, red). Meanwhile, the $\mathrm{NAD}(\mathrm{P}) \mathrm{H}$ overshoot did not change significantly suggesting that the overshoot may relate to some anaerobic (presumably glycolytic) part of the metabolic pathway (Kasischke et al., 2004). Modification of energy metabolism correlated with oxygen availability was also reflected in changes of neuronal electrical activity (Figure 3B). At lower rates of perfusion, LFPs were not only smaller throughout the train but revealed also different dynamics. This is shown in Figure 3C, depicting LFP integrals in 


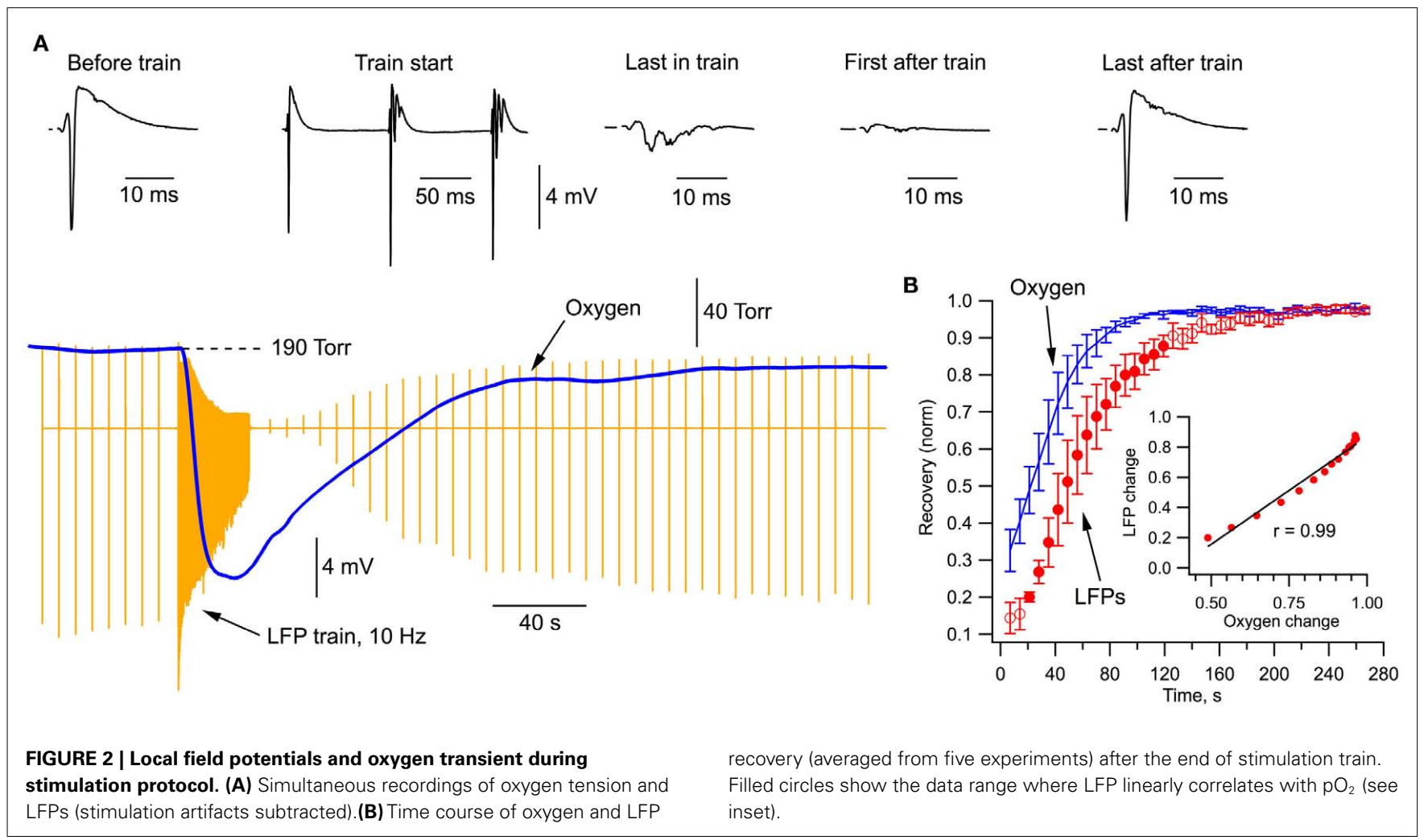

A

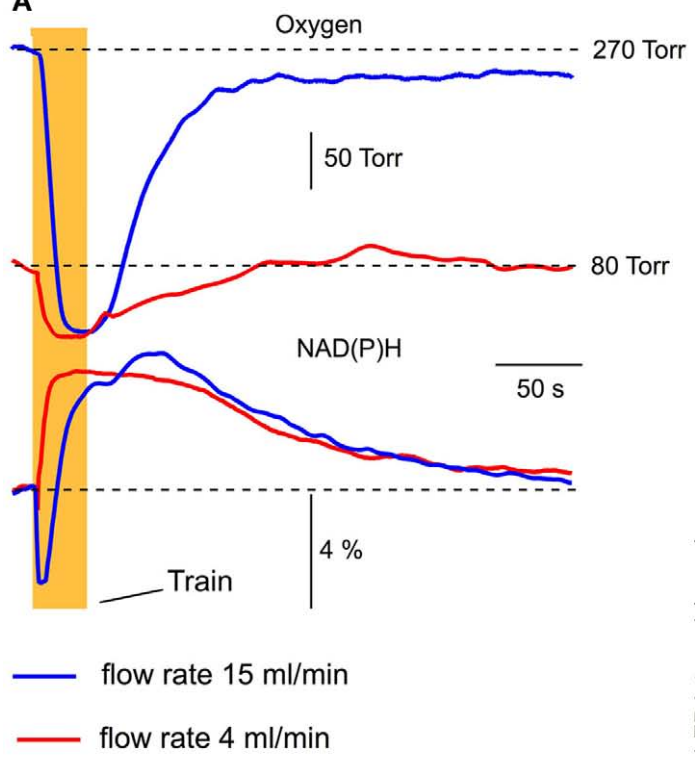

FIGURE 3 | Changes in oxygen transients, NAD(P)H signaling, and LFPs during train stimulation at different perfusion rates. (A) Oxygen transients and $\mathrm{NAD}(\mathrm{P}) \mathrm{H}$ autofluorescence recorded at different perfusion rates in the

B

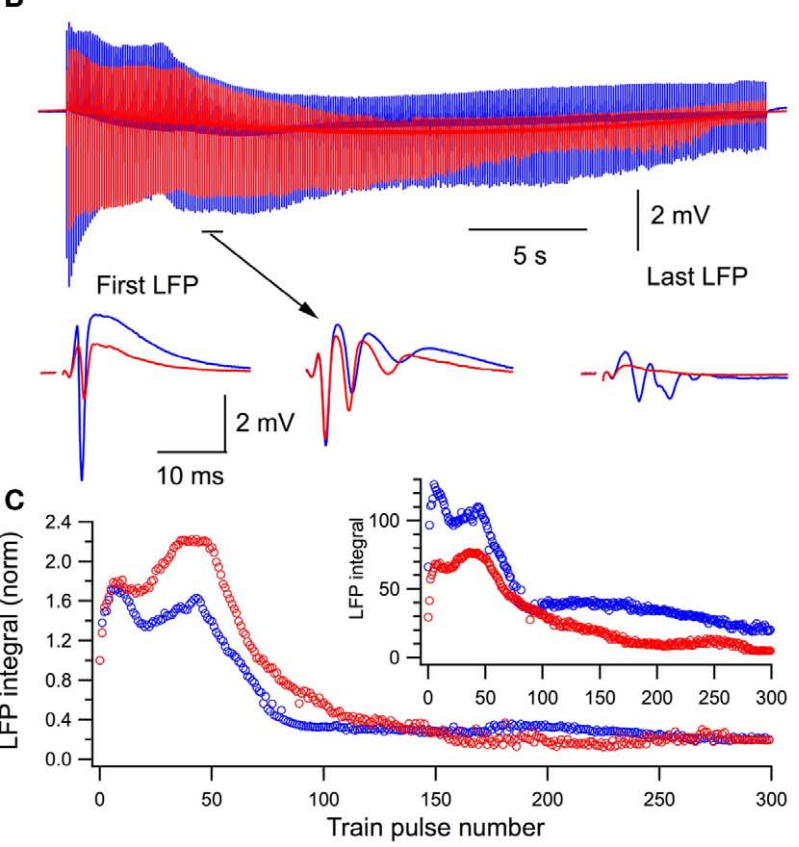

same slice. (B) LFPs during the stimulation train. (C) LFP integrals during the train stimulation calculated from original data (inset) and after normalization to the first response. the train obtained from raw data (Figure 3C inset) and from data normalized to the first response. Distinctions in LFP dynamics during the train stimulation at different oxygen availability conditions indicate that modulation of energy metabolism induces 
not only a "scaling" of synaptic response but also the qualitative changes in synaptic functioning. Figure 4Aa shows averaged normalized LFP synaptic components - fPSPs (see Materials and Methods) recorded at 15 and $4 \mathrm{ml} / \mathrm{min}$ solution flow rates in 15 slices. Note much stronger changes in synaptic responses at lower perfusion rates. Figure $4 \mathrm{Ab}$ shows a relative change of the first fPSPs in train: at $4 \mathrm{ml} / \mathrm{min}$ solution flow rate, the fPSP integral was $34 \pm 4 \%$ of that at $15 \mathrm{ml} / \mathrm{min}(p<0.001)$. Figures $4 \mathrm{~B}, \mathrm{C}$ show relative changes in the $\mathrm{NAD}(\mathrm{P}) \mathrm{H}$ profile and oxygen consumption at 15 and $4 \mathrm{ml} / \mathrm{min}$ superfusion: the $\mathrm{NAD}(\mathrm{P}) \mathrm{H}$ oxidation phase integral decreased by $88 \pm 4 \%(p<0.001)$ while the overshoot integral by $17 \pm 36 \%$ (not significant, $p>0.1$ ); the oxygen transient integral decreased by $67 \pm 6 \%(p<0.001)$ and the oxygen transient amplitude by $76 \pm 4 \%(p<0.001)$.

To rule out a possibility that the effect of solution flow rate on neuron electrical activity is induced by washing out of some substance(s) from slice tissue, we performed similar experiments ( $n=3$; not shown) at $15 \mathrm{ml} / \mathrm{min}$ superfusion with 95 and $\sim 50 \%$ oxygenation of ACSF. In line with previously published results (Garcia et al., 2010), a partial oxygenation produced similar to a slow perfusion effects on LFPs.

Therefore, a solution flow rate too low to provide the adequate slice oxygenation disrupts neuronal energy metabolism and induces the qualitative changes in neuronal properties, which underlie the function of synaptic transmission and cellular excitability.

\section{SPONTANEOUS SYNCHRONIZED NEURONAL ACTIVITY STRONGLY DEPENDS ON SLICE OXYGENATION}

Since slice oxygenation causes a pronounced effect on synaptic function, this may be also reflected in synchronous neuronal network discharges. To explore this issue, we induced the interictallike neuronal activity by $100 \mu \mathrm{M}$ of 4 -AP and measured both field potentials and $\mathrm{pO}_{2}$ in slices superfused at different rates $(n=5)$. Figure 5 demonstrates the original traces from such experiment. 4-AP applied at the solution flow rate of $15 \mathrm{ml} / \mathrm{min}$ evoked spontaneous discharges within a few minutes. Induced LFPs were also periodically recorded at different stages of experiment (Figure 5, top). After stabilization of synchronous activity, the solution flow rate was changed to $8 \mathrm{ml} / \mathrm{min}$, inducing a significant reduction in both the oxygen level and frequency of interictal discharges. Following the reduction of solution flow rate down to $4 \mathrm{ml} / \mathrm{min}, \mathrm{pO}_{2}$ dropped further and the amplitude and frequency of discharges decreased as well. Returning superfusion to $15 \mathrm{ml} / \mathrm{min}$ recovered both $\mathrm{pO}_{2}$ and synchronous network activity. Similar scenario was seen in five slices. Compared with $15 \mathrm{ml} / \mathrm{min}$ superfusion, the mean frequency of synchronous discharges decreased by $76 \pm 5 \%$ at $4 \mathrm{ml} / \mathrm{min}(p<0.001, n=5)$. Therefore, insufficient
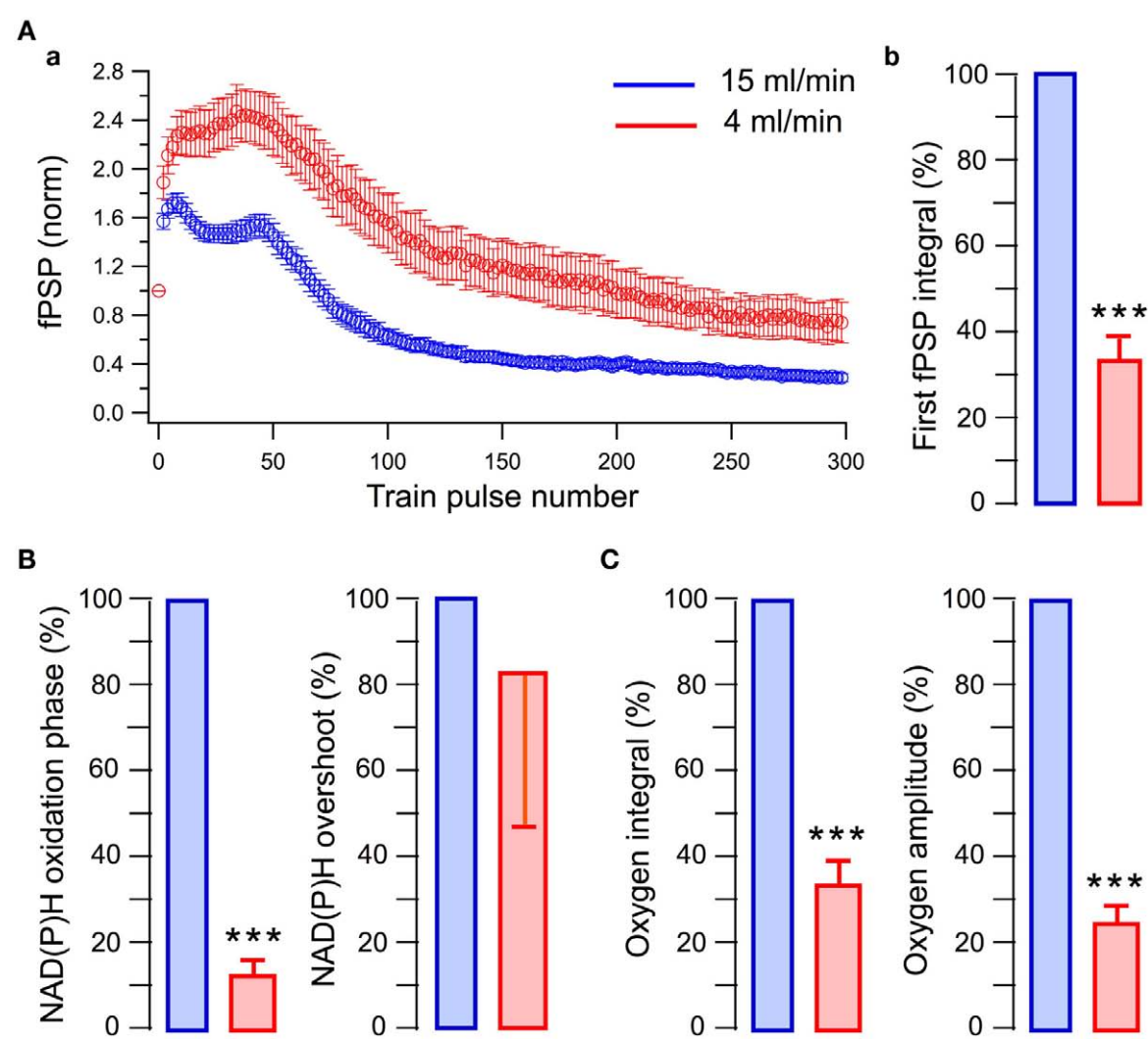

C
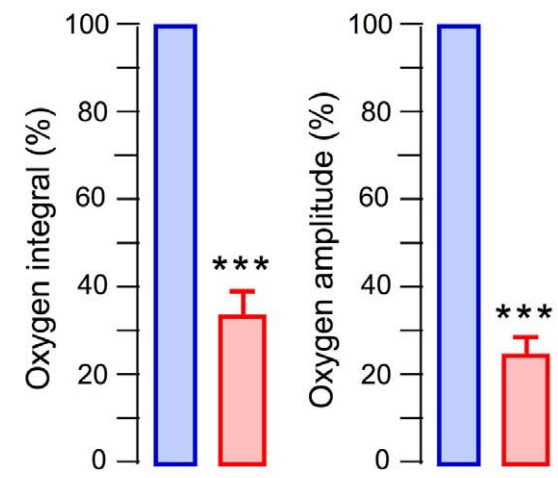

FIGURE 4 | Short-term synaptic plasticity and oxidative metabolism strongly depend on the rate of perfusion (oxygen supply). (A, a) Integrals of fPSPs induced by the train stimulation and normalized to the first response. Note much stronger relative changes in consequent fPSPs at smaller perfusion rate; (b) Integrals of the first fPSPs in the train. (B) $N A D(P) H$ signaling parameters at different perfusion rates. (C) Oxygen transient parameters at different perfusion rates. 


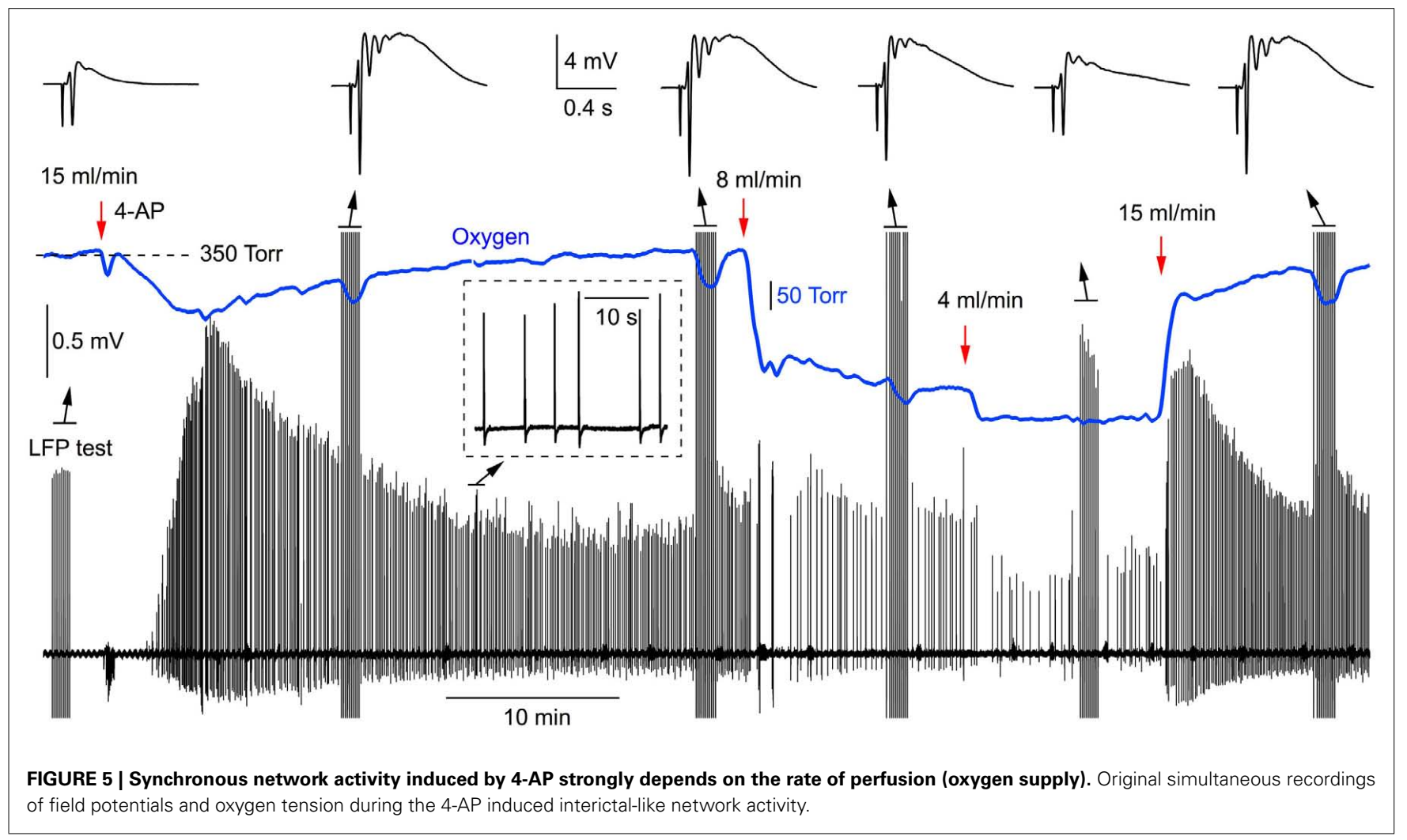

slice oxygenation strongly affects the ability of neuronal network for spontaneous synchronous activity induced by 4 -AP.

\section{OXIDATIVE METABOLISM AND SYNAPTIC FUNCTION ARE ENHANCED IN ACSF ENRICHED BY ENERGY SUBSTRATES}

We have recently demonstrated in neonatal slices that supplementation of glucose in ACSF with oxidative energy substrates enhances both the oxidative metabolism and synaptic function (Ivanov et al., 2011). In the present study, we explored this issue using more mature brain slices. For this purpose, we utilized the energy substrate-enriched ACSF (eACSF; $5 \mathrm{mM}$ glucose $+5 \mathrm{mM}$ pyruvate $+4 \mathrm{mM}$ DL-BHB). The composition of eACSF has been discussed elsewhere (Holmgren et al., 2010; Zilberter et al., 2010). Note that we did not attempt to reproduce the composition of extracellular brain fluid but rather attempted to provide sufficient oxidative energy substrates for neuronal energy demands.

Figure 6Aa shows that compared to standard ACSF conditions, oxygen consumption during train stimulation is increased in eACSF and this is accompanied by a considerable augmentation of the NAD $(\mathrm{P}) \mathrm{H}$ oxidation phase as well as a decrease in $\mathrm{NAD}(\mathrm{P}) \mathrm{H}$ overshoot. The enhancement of oxidative metabolism is paralleled by a change in LFP dynamics throughout the train (Figure 6Ab,c). In six slices (Figure 6B), the first LFPs in the train did not differ significantly while subsequent LFPs were significantly larger in eACSF. Meanwhile, the oxygen consumption increased in eACSF by $18 \pm 3 \%$ (Figure $6 \mathrm{C} ; p<0.005$ ), $\mathrm{NAD}(\mathrm{P}) \mathrm{H}$ oxidation phase by $140 \pm 33 \%$ (Figure $6 \mathrm{D} ; p<0.001$ ) and $\mathrm{NAD}(\mathrm{P}) \mathrm{H}$ overshoot decreased by $60 \pm 7 \%$ (Figure 6D; $p<0.001$ ). Therefore, in eACSF, the aerobic energy metabolism is enhanced compared to standard ACSF.

If the last statement is correct eACSF should lose its efficacy at conditions of oxygen deficiency. In five experiments, we compared the effects of ACSF and eACSF at lower slice oxygenation using the $8-\mathrm{ml} / \mathrm{min}$ superfusion. In contrast to the results obtained at high perfusion rate $(15 \mathrm{ml} / \mathrm{min})$, LFPs did not differ significantly during the stimulation train (Figure 7A). In addition, transition to eACSF had no significant effect on the $\mathrm{NAD}(\mathrm{P}) \mathrm{H}$ oxidation phase (integral increased by $37 \pm 31 \%, n=5, p>0.3$; not shown) indicating that supplemental substrates were not as efficient at lower perfusion rates when compared to their effect at $15 \mathrm{ml} / \mathrm{min}$ superfusion. This conclusion was further confirmed by comparison of $\mathrm{NAD}(\mathrm{P}) \mathrm{H}$ signals recorded in eACSF at 15 and $8 \mathrm{ml} / \mathrm{min}$ flow rates (Figures 7B,C). Lower perfusion rate (i.e., oxygenation) induced a substantial decrease in $\mathrm{NAD}(\mathrm{P}) \mathrm{H}$ oxidation phase integral (by $77 \pm 5 \%, n=5 ; p<0.001$, Figures 7B,C) as well as an increase of overshoot (by $58 \pm 19 \%, n=5$; $p<0.01$, Figures 7B,C). Importantly, these changes in the efficacy of aerobic metabolism occurred in the range of basal $\mathrm{pO}_{2}$ (>150 Torr) considerably exceeding the physiological $\mathrm{pO}_{2}$ levels in vivo (20-40 Torr; Erecinska and Silver, 2001; Masamoto et al., 2003, 2007; Takano et al., 2007), suggesting divergent oxygen requirements of neurons in slices.

\section{LACTATE-BASED EACSF INDUCES SIMILAR TO PYRUVATE-BASED EACSF EFFECTS}

Lactate has been suggested as a preferential fuel for cortical neurons during intense network activity (Wyss et al., 2011). We therefore examined the effects of a lactate-based 

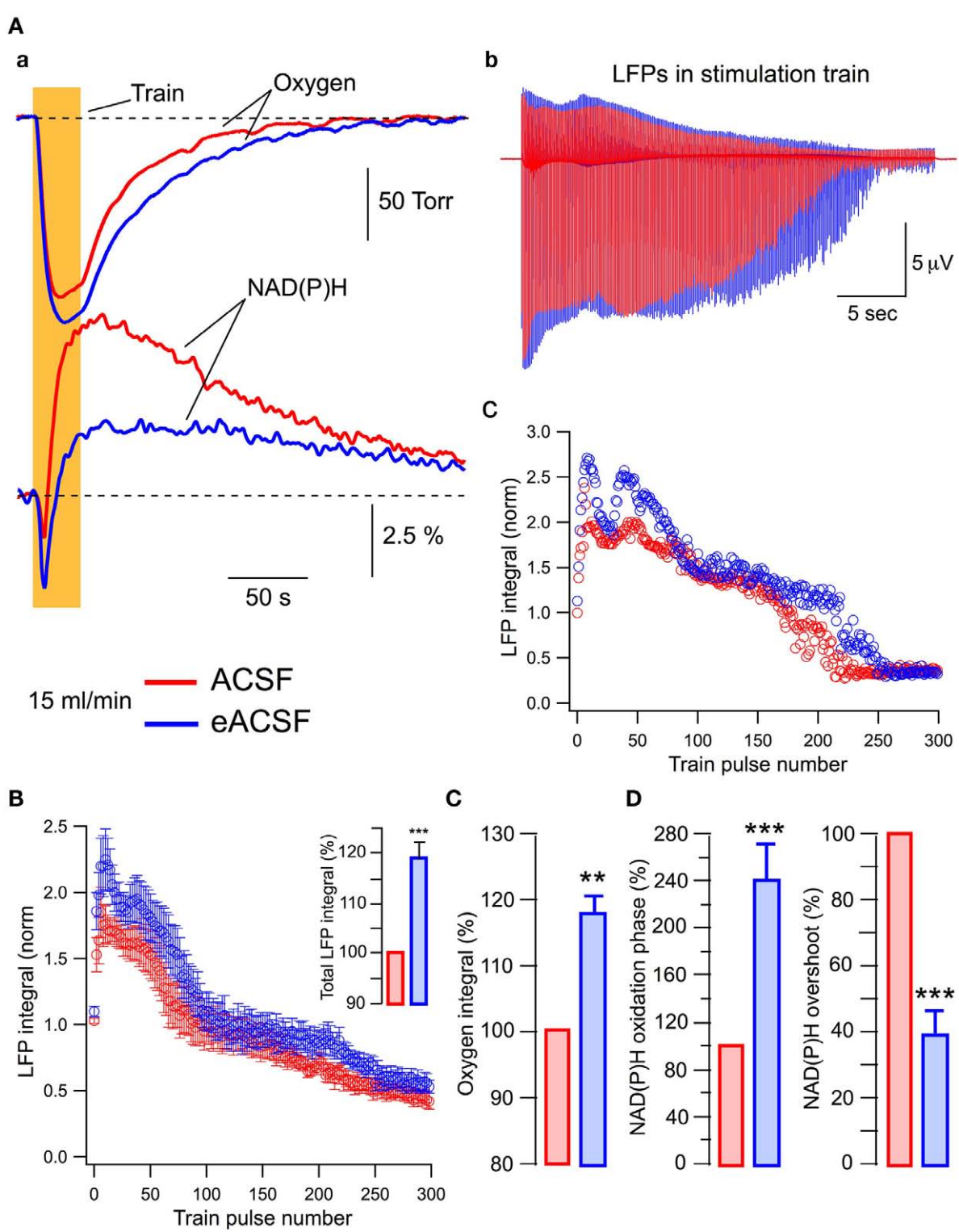

C

D

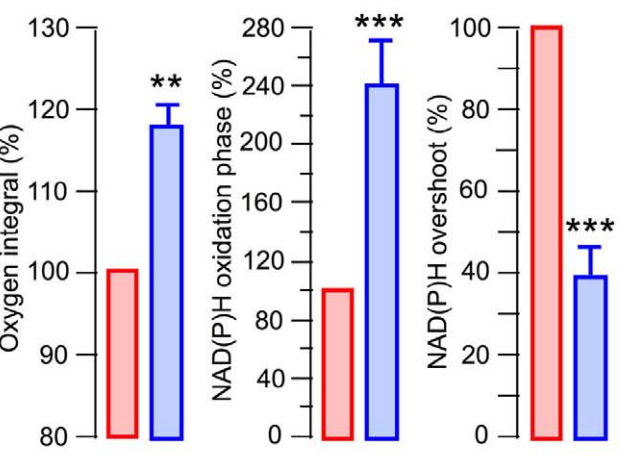

FIGURE 6 | At sufficient oxygen supply, energy substrates supplemented to glucose enhance both oxidative metabolism and synaptic function. In all experiments slices were superfused at $15 \mathrm{ml} / \mathrm{min}$. (A) Original traces of (a) oxygen and $\mathrm{NAD}(\mathrm{P}) \mathrm{H}$ transients and (b) LFPs during the train (stimulation artifact subtracted)

eACSF ( $5 \mathrm{mM}$ glucose $+5 \mathrm{mM}$ L-lactate $+4 \mathrm{mM}$ DL-BHB). Similar to the pyruvate-based eACSF, both aerobic metabolism and synaptic function were enhanced in the lactatebased eACSF compared to standard ACSF (Figure 8). In particular, the total LFP integral was by $27 \pm 7.5 \%$ larger (Figure 8A; $n=5, p<0.005)$. The oxygen consumption induced by stimulation train increased by $68 \pm 22 \%$ (Figure $8 \mathrm{~B} ; n=4$, $p<0.03)$; the $\mathrm{NAD}(\mathrm{P}) \mathrm{H}$ oxidation phase increased by $143 \pm 12 \%$ (Figure 8C; $n=5, p<0.001)$ while the $\mathrm{NAD}(\mathrm{P}) \mathrm{H}$ overshoot decreased by $64 \pm 8 \%$ (Figure $8 \mathrm{C} ; n=5, p<0.002$ ). Therefore, at sufficient oxygen supply, the supplementing glucose recorded in ACSF (red) and eACSF (blue). The normalized LFP integrals during the train are shown in (c). (B) Statistical summary (six slices) of LFP integrals during the train. The inset shows total LFP integrals (summation of all LFP integrals in the train). (C,D) Show statistical summary of oxygen and $\mathrm{NAD}(\mathrm{P}) \mathrm{H}$ parameters. in ACSF with different combinations of energy substrates improves both oxidative metabolism and efficacy of synaptic function.

\section{DISCUSSION}

Our results demonstrate that synaptic efficacy, synaptic plasticity, and the neuronal network's potential for synchronized activity all strongly depend on oxidative energy metabolism. This conclusion is specifically important for the studies on brain slices where the oxygen delivery to neurons may be compromised by experimental conditions. 
A
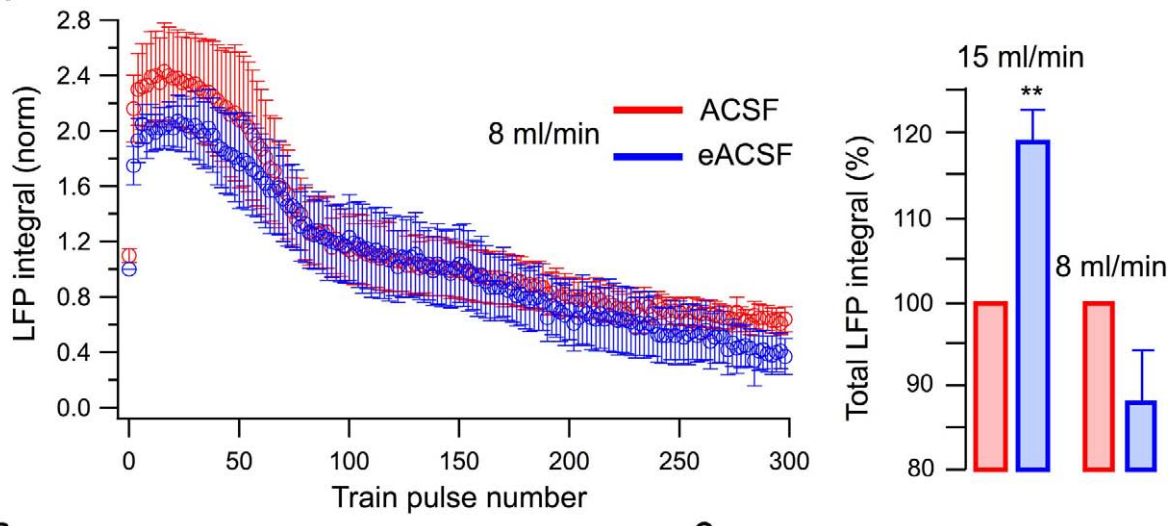

B

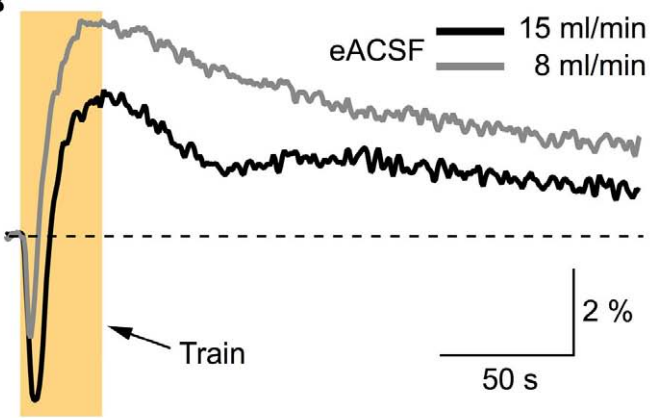

C

FIGURE 7 | Supplementary energy substrates are inefficient at a low perfusion rate (low oxygen supply). (A) Left: summary of LFPs recorded in ACSF and eACSF in five slices superfused at $8 \mathrm{ml} / \mathrm{min}$. Right: comparison of total LFP integrals at 15

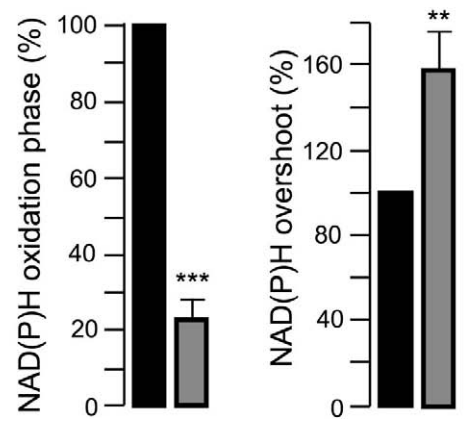

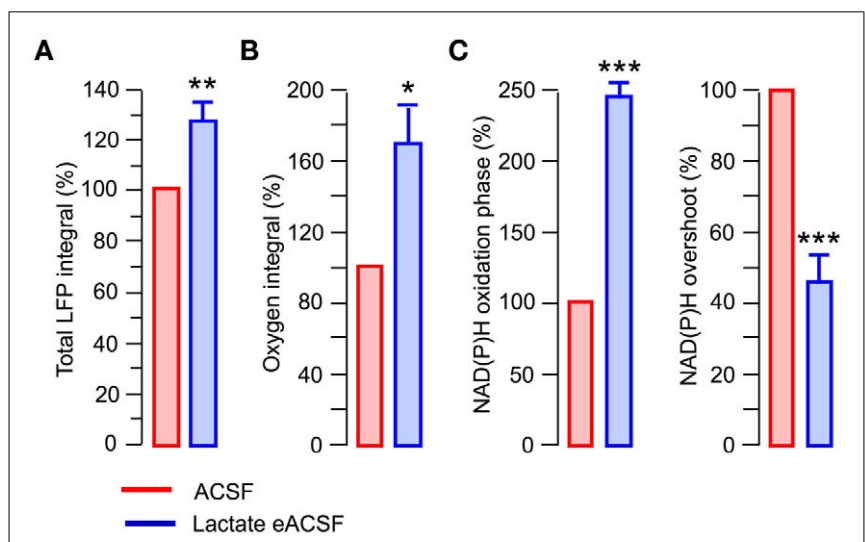

FIGURE 8 | At sufficient oxygen supply, lactate-based eACSF causes similar effects as pyruvate-based eACSF. In all experiments slices were superfused at $15 \mathrm{ml} / \mathrm{min}$. (A) Total LFP integrals in the stimulation train (five slices). (B,C) Oxygen and NAD(P)H signaling parameters.

\section{OXYGEN DELIVERY TO NEURONS IN SLICES AFFECTS BOTH SYNAPTIC EFFICACY AND SYNAPTIC PLASTICITY}

Hippocampal LFPs revealed a strong dependence on oxygen distribution in a slice. Similar observations on P27-P40 rats (Garcia et al., 2010) and on neonatal (P4-P7) mice (Ivanov et al., 2011) and $8 \mathrm{ml} / \mathrm{min}$ perfusion rate. (B) Example of original traces of $\mathrm{NAD}(\mathrm{P}) \mathrm{H}$ signaling recorded in eACSF at different perfusion rates. (C) Summary of changes in $\mathrm{NAD}(\mathrm{P}) \mathrm{H}$ signaling recorded in eACSF at different perfusion rates. have been reported previously although the underlying mechanism of synaptic function reliance on oxygen is unclear. Severe decrease in synaptic transmission was observed during slice exposure to a complete hypoxia (Pena and Ramirez, 2005) and in such cases a decline in cellular ATP level was suggested as one reason for the failure of synaptic function (Kass and Lipton, 1982; Lipton and Whittingham, 1982). It was also demonstrated that hypoxia had a direct influence on the vesicular release mechanisms (Fleidervish et al., 2001). Indeed, multiple studies of glutamatergic transmitter release from nerve terminals demonstrated prominent dependence of the release machinery on energy metabolism (Erecinska et al., 1996; Nicholls, 2003). Therefore, insufficient oxygen availability leads to the lowered oxidative metabolism and as the result may inhibit glutamate release from the pyramidal cell terminals. Interestingly, synaptic plasticity (see Figure 4Aa) is more striking at smaller perfusion rates (lower slice oxygenation). One possible reason for this may be an enhanced accumulation of $\mathrm{Ca}^{2+}$ in the nerve terminals due to its insufficient ATP-dependent extrusion between pulses. The mechanism of this phenomenon, however, requires further clarification.

\section{SYNCHRONIZED SPONTANEOUS NETWORK ACTIVITY DEPENDS ON OXYGEN DELIVERY}

Deficiency in oxidative metabolism results not only in downregulation of synaptic function but also strongly affects the ability 
of neuronal network for synchronous discharges. Recently, Hajos et al. (2009) reported that both spontaneously occurring sharp wave-ripple oscillations and cholinergically induced fast oscillations in submerged hippocampal slices could be observed only at the solution flow rates providing sufficient slice oxygenation (about $6 \mathrm{ml} / \mathrm{min}$ in their custom dual-sided perfusion chamber). Strong dependence of cholinergically induced gamma oscillations on oxygen pressure was also demonstrated on the organotypic hippocampal slice cultures (Huchzermeyer et al., 2008). The importance of appropriate slice oxygenation for the approximation of physiological-like network properties was discussed recently by Hajos and Mody (2009). In our experiments (see Figure 4), both the amplitude and frequency of 4-AP induced spontaneous discharges decreased sharply with the drop in slice oxygenation (switch of perfusion from 15 to $4 \mathrm{ml} / \mathrm{min}$ ). Therefore, these results suggest that the inadequate oxidative metabolism, e.g., due to insufficient slice oxygenation, considerably modifies network properties required for the synchronous neuronal activity, either intrinsic or induced.

\section{NEURONAL ACTIVITY VS. OXYGEN PRESSURE IN VIVO AND IN SLICES}

Since mitochondrial oxidative phosphorylation is coupled to oxygen reduction and is responsible for most of the cellular oxygen consumption, the rate of respiration is a measure of the rate of ATP synthesis. In brain, the respiratory rate may be controlled within a wide dynamic range and in the normal steady-state of cellular metabolism it provides ATP at precisely the rate needed to cover cell energy demands (Wilson et al., 1979; Erecinska and Silver, 2001). The ambient oxygen concentration in rat hippocampus in vivo is about 20-30 Torr (Erecinska and Silver, 2001; Kasischke et al., 2011). Therefore, although a relatively low oxygen environment is natural for a significant fraction of cortical neurons (Gjedde, 2002; Ndubuizu and Lamanna, 2007), this environment is still capable of efficiently supporting normal cortical function.

The obvious question therefore is how to reconcile the in vivo observations with the apparent much stronger oxygen dependence of neuronal activity in slices. Indeed, strong changes in LFP values occurred in slices in the range of oxygen tensions where the lower level exceeded the normal oxygen levels in vivo (Garcia et al., 2010; Ivanov et al., 2011). Garcia et al. (2010) observed that a single stimulation-evoked population response nearly disappeared after a switch of solution oxygenation from $0.95 \mathrm{ATA} \mathrm{O}_{2}$ to 0.60 ATA $\mathrm{O}_{2}$, although the minimal oxygen pressure in a slice core was about 100 Torr. Hyperoxic conditions were required to obtain physiological-like spontaneous gamma oscillations in acute slices (Fisahn et al., 1998; Hajos et al., 2009; Kann et al., 2011). Huchzermeyer et al. (2008) noted that gamma oscillations in cultured (organotypic) hippocampal slices strongly decreased at $20 \% \mathrm{O}_{2}$ in perfusate (compared to $95 \%$ ) despite the fact that the baseline $\mathrm{pO}_{2}$ was about 50 Torr in a slice core, decreasing during oscillations to about 20 Torr and still being in the range of interstitial $\mathrm{pO}_{2}$ values in air-respiring rodents (Erecinska and Silver, 2001; Takano et al., 2007).

On the other hand, when oxygen tension in vivo is comparable to those required for neuronal function in slices, oxygen is obviously toxic. For instance, $\mathrm{O}_{2}$ toxicity occurred in awake rats breathing oxygen at $>4.0$ ATA $\mathrm{O}_{2}$ ( $>400$ Torr in the brain; Demchenko et al., 2005), manifesting in tonic clonic seizures (Simon and Torbati, 1982). However, seizures were not observed in hippocampal slices exposed to similar ( $>4$ ATA) $\mathrm{pO}_{2}$ levels (Garcia et al., 2010). Contrary to LFPs recorded in slices (Garcia et al., 2010), cortical LFPs induced by somatosensory stimulation in anesthetized rats were similar at 1 (about 40 Torr $\mathrm{pO}_{2}$ ), 3 , or 4 ATA ( $>400$ Torr $\mathrm{pO}_{2}$ ) of breathing oxygen (Lindauer et al., 2010b), indicating much lower oxygen dependence of neuronal activity in vivo.

In agreement with previous reports, our results demonstrate that LFPs induced by periodic single stimulations significantly decreased with the reduction of $\mathrm{pO}_{2}$ to values higher than the upper level of physiological range (see Figure 1). Spontaneous synchronous network activity revealed a pronounced sensitivity to oxygen above the physiological range (Figure 5).

Our data also indicate an uncoupling between oxygen pressure measured in slice tissue and neuronal energy metabolism (see also Turner et al., 2007). At oxygen tensions that might be considered as "hyperoxic," the prolonged synaptic stimulationinduced $\mathrm{NAD}(\mathrm{P}) \mathrm{H}$ signal showed dynamics abnormal for the in vivo observations (Rosenthal and Jobsis, 1971; Lothman et al. 1975; Lamanna et al., 1984; Mayevsky and Chance, 2007), namely the large overshoot and small oxidative phase (see Figure 3). Interestingly, at such oxygenation levels, supplementation of glucose with other oxidative energy substrates (pyruvate, lactate, and $\mathrm{BHB}$ ) increased the $\mathrm{NAD}(\mathrm{P}) \mathrm{H}$ oxidation phase substantially. However, the effect of these substrates practically disappeared at lower oxygenation levels (see Figures 6 and 7), indicating that despite the $\mathrm{pO}_{2}$ being above the physiological range, the oxygen supply was insufficient for oxidative phosphorylation. Therefore there exists an apparent discrepancy in the definition of "normoxic" tissue oxygen pressure between the in vivo and slice conditions.

One possible reason for such a discrepancy may be compromised metabolism in brain slices, presumably as a consequence of traumatic cutting procedure (Rolleston and Newsholme, 1967; Benjamin and Verjee, 1980; Whittingham et al., 1984; Zur Nedden et al., 2011). This results in a substantial decrease of high energy phosphates, in particular, about $50 \%$ lower than in vivo concentrations of ATP and PCr (Whittingham et al., 1984) or $40-60 \%$ smaller the total adenine nucleotide pool (Whittingham et al., 1984; Zur Nedden et al., 2011). It was also reported that the rate of glycolysis in brain slices (Rolleston and Newsholme, 1967; Benjamin and Verjee, 1980) is $50 \%$ or less of that in vivo.

In addition, the dynamics of $\mathrm{pO}_{2}$ variability during neuronal activity differs radically between the intact brain and slices. In vivo, changes in neuronal activity are tightly coupled to changes in regional metabolism, local cerebral blood flow, and oxygenation (Raichle and Mintun, 2006; Masamoto et al., 2008; Lindauer et al., 2010b; Vazquez et al., 2010) although the factors regulating changes in cerebral blood flow during physiological activation remain the subject of debate (Raichle and Mintun, 2006; Verweij et al., 2007; Lindauer et al., 2010a,b). As the result, after the onset of neuronal activity, the tissue $\mathrm{pO}_{2}$ can exceed the required level by 1.5-2 times (Erecinska and Silver, 2001; 
Masamoto et al., 2003, 2007). Note also that the distance from any neuron to the nearest blood vessel providing oxygen supply does not exceed $25 \mu \mathrm{m}$ (Erecinska and Silver, 2001; Masamoto et al., 2004; Abbott et al., 2010). However, even at such a favorable for the oxygen delivery situation, the oxygen distribution in cortical tissue is not homogenous and local regions of a minor hypoxia can exist (Kasischke et al., 2011). In slices, oxygen is delivered to neurons by diffusion from the superfusing solution. Compared to the rate of oxygen consumption by neurons, the rate of oxygen diffusion in slice tissue is very slow. Indeed, analysis of our data showed that at the beginning of train stimulation, $\mathrm{pO}_{2}$ declines with a mean rate of about 20 Torr/s (see $\mathrm{pO}_{2}$ transients in Figures $\mathbf{2 A}, \mathbf{3 A}$, and $\mathbf{6 A}$ ). This value is likely underestimated because the response time of oxygen probe could be as long as $3 \mathrm{~s}$. After the train, $\mathrm{pO}_{2}$ recovers up to the initial level for longer than $100 \mathrm{~s}$. The highest rate of recovery is about $4 \mathrm{Torr} / \mathrm{s}$ that is five times slower than $\mathrm{O}_{2}$ consumption at the beginning of stimulation episode. Therefore, during neuronal activity, the oxygen consumption in vicinity of neurons is not followed by the oxygen recovery. Although during neuronal activity the oxygen electrode in slice tissue registers a relatively high integral oxygen pressure, the real oxygen levels in neuronal microenvironment may be extremely inhomogeneous (see also Turner et al., 2007; Huchzermeyer et al., 2008). Definitely, this issue requires further investigation. It is evident, however, that there is a substantial discrepancy between functional effects of similar oxygen levels in the brain and slices. This suggests that analyzing the link between neuronal functions and $\mathrm{pO}_{2}$ in slices (e.g., "normoxic" or "hyperoxic"), the direct reference to $\mathrm{pO}_{2}$ in vivo may be inadequate.

One very attractive, although yet speculative, explanation of the extremely high demands of slice neuronal activity for oxygen is associated with the mitochondrial anion-carrier proteins that are located on the inner mitochondrial membrane and are called uncoupling proteins (UCPs; Mattson and Liu, 2003; Andrews et al., 2005). UCPs provide a path for protons to return to the matrix without passing through ATP-synthase and therefore the energy derived from oxidation of substrates does not result in the production of ATP but is instead released as heat. UCPs can be activated by free radicals and free fatty acids. UCPs have been identified and shown to be highly expressed in the CNS including cortex and hippocampus (Andrews et al., 2005). Interestingly, strong activation of UCPs has been documented during acute brain trauma and stroke/ischemia (Sullivan et al., 2004; Kim-Han and Dugan, 2005). From these facts, it is plausible to suggest that the acute preparation of brain slices may lead to the activation of UCPs in neurons. This would result in "shunting" of mitochondrial oxidative phosphorylation and a subsequent strong increase in the amount of oxygen required for the production of necessary amount of ATP. In such a case, the dependence of neuronal activity in slices on oxygen tension would be shifted toward higher $\mathrm{pO}_{2}$ values.

\section{GLUCOSE DOES NOT FULLY COVER ENERGY DEMANDS DURING NEURONAL ACTIVITY}

The use of high concentration ( $10 \mathrm{mM}$ or above) of glucose as the sole energy substrate in ACSF does not seem to be adequate when mimicking in vivo extracellular neuronal environment (Barros et al., 2007; Hajos and Mody, 2009; Zilberter et al., 2010). For instance, it is firmly established that the glucose concentration in cortical ECF is about $1-2 \mathrm{mM}$ and is comparable and even lower (during intense neuronal activity) to the concentration of lactate. A number of recent studies (Castro et al., 2009; Pellerin, 2010), including those in vivo (Suzuki et al., 2011; Wyss et al., 2011), provide evidence that lactate is a key energy substrate for neuronal aerobic metabolism. In the active brain, the energy substrate pool in neuronal vicinity is the result of complex blood vessel-astrocyte-neuron interaction (Abbott et al., 2010; Pellerin, 2010). Therefore, a priori suggestion that glucose alone is able to cover fully energy requirements during neuron activation in slices seems to be unsubstantiated. The importance of modifying the ACSF composition to better approximate physiological conditions has been highlighted in recent reviews (Hajos and Mody, 2009; Zilberter et al., 2010).

Our results demonstrate that oxidative metabolism and synaptic function are indeed both enhanced in the energy substrateenriched solution (eACSF). At high perfusion rates, both versions of eACSF (pyruvate or lactate-based) significantly increased the oxygen consumption, $\mathrm{NAD}(\mathrm{P}) \mathrm{H}$ oxidation phase, and efficacy of synaptic transmission during prolonged stimulation (Figures 6 and 8). Glucose substitution also induced a decrease in NAD $(\mathrm{P}) \mathrm{H}$ overshoot. It is possible that the oxidation phase of $\mathrm{NAD}(\mathrm{P}) \mathrm{H}$ enhanced in eACSF partially masks the actual reduction time course. Clarification of the origin of $\mathrm{NAD}(\mathrm{P}) \mathrm{H}$ overshoot requires further studies. We have previously observed similar effects of energy substrates on neonatal slices (Ivanov et al., 2011). Therefore, in slices as well as in vivo, the ability of glucose to maintain energy metabolism is limited and neuronal energy supply should be supported by other oxidative substrates.

\section{CONCLUSION}

Our results confirm that in acute brain slices, the basic neuronal parameters underlying excitability strongly depend on oxidative energy metabolism. We show that the state of energy metabolism is highly sensitive to the availability of oxygen in slice tissue. The pathway for ATP synthesis is apparently compromised in brain slices and therefore the reliance of neuronal activity on oxygen tension is clearly shifted toward considerably larger $\mathrm{pO}_{2}$ values. In addition, during neuronal activity, glucose alone may not be able to fully cover the neuronal energy demands and therefore adequate support of oxidative metabolism by other energy substrates complementary to glucose is required. Given the fact that in a number of electrophysiological studies neither the oxygen tension in a slice nor the energy substrate composition in ACSF have been controlled, our results call for the careful reconsideration of experimental approaches to neuronal activity studies in vitro.

\section{ACKNOWLEDGMENTS}

We thank Dr. T. Zilberter for the valuable discussion and help in the preparation of manuscript. This study was supported by the European Union Seventh Framework "MEMOLOAD” grant (HEALTH-F2-2007-201159; Yuri Zilberter) and French National Research Agency “METANEX” grant (ANR-2010-BLAN-1443-01; Anton Ivanov and Yuri Zilberter). 


\section{REFERENCES}

Abbott, N. J., Patabendige, A. A., Dolman, D. E., Yusof, S. R., and Begley, D. J. (2010). Structure and function of the blood-brain barrier. Neurobiol. Dis. 37, 13-25.

Andrews, Z. B., Diano, S., and Horvath, T. L. (2005). Mitochondrial uncoupling proteins in the CNS: in support of function and survival. Nat. Rev. Neurosci. 6, 829-840.

Barros, L. F., Bittner, C. X., Loaiza, A., and Porras, O. H. (2007). A quantitative overview of glucose dynamics in the gliovascular unit. Glia 55 , 1222-1237.

Benjamin, A. M., and Verjee, Z. H. (1980). Control of aerobic glycolysis in the brain in vitro. Neurochem. Res. 5, 921-934.

Bolanos, J. P., Almeida, A., and Moncada, S. (2010). Glycolysis: a bioenergetic or a survival pathway? Trends Biochem. Sci. 35, 145-149.

Castro, M. A., Beltran, F. A., Brauchi, S., and Concha, I. I. (2009). A metabolic switch in brain: glucose and lactate metabolism modulation by ascorbic acid. J. Neurochem. 110, 423-440.

Coelho, J. E., De Mendonca, A., and Ribeiro, J. A. (2000). Presynaptic inhibitory receptors mediate the depression of synaptic transmission upon hypoxia in rat hippocampal slices. Brain Res. 869, 158-165.

Demchenko, I. T., Luchakov, Y. I., Moskvin, A. N., Gutsaeva, D. R., Allen, B. W., Thalmann, E. D., and Piantadosi, C. A. (2005). Cerebral blood flow and brain oxygenation in rats breathing oxygen under pressure. J. Cereb. Blood Flow Metab. 25, 1288-1300.

Erecinska, M., Nelson, D., and Silver, I. A. (1996). Metabolic and energetic properties of isolated nerve ending particles (synaptosomes). Biochim. Biophys. Acta 1277, 13-34.

Erecinska, M., and Silver, I. A. (2001). Tissue oxygen tension and brain sensitivity to hypoxia. Respir. Physiol. 128, 263-276.

Feig, S., and Lipton, P. (1990). Nmethyl-D-aspartate receptor activation and $\mathrm{Ca} 2+$ account for poor pyramidal cell structure in hippocampal slices. J. Neurochem. 55, 473-483.

Fisahn, A., Pike, F. G., Buhl, E. H., and Paulsen, O. (1998). Cholinergic induction of network oscillations at $40 \mathrm{~Hz}$ in the hippocampus in vitro. Nature 394, 186-189.

Fleidervish, I. A., Gebhardt, C., Astman, N., Gutnick, M. J., and Heinemann, U. (2001). Enhanced spontaneous transmitter release is the earliest consequence of neocortical hypoxia that can explain the disruption of normal circuit function. $J$. Neurosci. 21, 4600-4608.

Foster, K. A., Beaver, C. J., and Turner, D. A. (2005). Interaction between tissue oxygen tension and $\mathrm{NADH}$ imaging during synaptic stimulation and hypoxia in rat hippocampal slices. Neuroscience 132, 645-657.

Foster, K. A., Galeffi, F., Gerich, F. J., Turner, D. A., and Muller, M. (2006). Optical and pharmacological tools to investigate the role of mitochondria during oxidative stress and neurodegeneration. Prog. Neurobiol. 79, 136-171.

Frenguelli, B. G., Llaudet, E., and Dale, N. (2003). High-resolution realtime recording with microelectrode biosensors reveals novel aspects of adenosine release during hypoxia in rat hippocampal slices. J. Neurochem. 86, 1506-1515.

Garcia, A. J. III, Putnam, R. W., and Dean, J. B. (2010). Hyperbaric hyperoxia and normobaric reoxygenation increase excitability and activate oxygen-induced potentiation in CAl hippocampal neurons. J. Appl. Physiol. 109, 804-819.

Gjedde, A. (2002). Cerebral blood flow change in arterial hypoxemia is consistent with negligible oxygen tension in brain mitochondria. $\mathrm{Neu}$ roimage $17,1876-1881$.

Hajos, N., Ellender, T. J., Zemankovics, R., Mann, E. O., Exley, R., Cragg, S. J., Freund, T. F., and Paulsen, O. (2009). Maintaining network activity in submerged hippocampal slices: importance of oxygen supply. Eur. J. Neurosci. 29, 319-327.

Hajos, N., and Mody, I. (2009). Establishing a physiological environment for visualized in vitro brain slice recordings by increasing oxygen supply and modifying aCSF content. J. Neurosci. Methods 183, 107-113.

Holmgren, C. D., Mukhtarov, M., Malkov, A. E., Popova, I. Y., Bregestovski, P., and Zilberter, Y. (2010). Energy substrate availability as a determinant of neuronal resting potential, GABA signaling and spontaneous network activity in the neonatal cortex in vitro. $J$. Neurochem. 112, 900-912.

Huchzermeyer, C., Albus, K., Gabriel, H. J., Otahal, J., Taubenberger, N., Heinemann, U., Kovacs, R., and Kann, O. (2008). Gamma oscillations and spontaneous network activity in the hippocampus are highly sensitive to decreases in $\mathrm{pO} 2$ and concomitant changes in mitochondrial redox state. J. Neurosci. 28, 1153-1162.

Ivanov, A., Mukhtarov, M., Bregestovski, P., and Zilberter, Y. (2011). Lactate effectively covers energy demands during neuronal network activity in neonatal hippocampal slices. Front. Neuroenergetics 3:2. doi:10.3389/fnene.2011.00002

Kann, O., Huchzermeyer, C., Kovacs, R., Wirtz, S., and Schuelke, M. (2011). Gamma oscillations in the hippocampus require high complex I gene expression and strong functional performance of mitochondria. Brain 134, 345-358.

Kasischke, K. A., Lambert, E. M., Panepento, B., Sun, A., Gelbard, H. A., Burgess, R. W., Foster, T. H., and Nedergaard, M. (2011). Twophoton NADH imaging exposes boundaries of oxygen diffusion in cortical vascular supply regions. J. Cereb. Blood Flow Metab. 31 68-81.

Kasischke, K. A., Vishwasrao, H. D. Fisher, P. J., Zipfel, W. R., and Webb, W. W. (2004). Neural activity triggers neuronal oxidative metabolism followed by astrocytic glycolysis. Science 305, 99-103.

Kass, I. S., and Lipton, P. (1982). Mechanisms involved in irreversible anoxic damage to the in vitro rat hippocampal slice. J. Physiol. (Lond.) 332, 459-472.

Kim-Han, J. S., and Dugan, L. L. (2005). Mitochondrial uncoupling proteins in the central nervous system. Antioxid. Redox Signal. 7, 1173-1181.

Klaidman, L. K., Leung, A. C., and Adams, J. D. Jr. (1995). Highperformance liquid chromatography analysis of oxidized and reduced pyridine dinucleotides in specific brain regions. Anal. Biochem. 228 312-317.

Lamanna, J. C., Light, A. I., Peretsman, S. J., and Rosenthal, M. (1984). Oxygen insufficiency during hypoxic hypoxia in rat brain cortex. Brain Res. 293, 313-318.

Lindauer, U., Dirnagl, U., Fuchtemeier, M., Bottiger, C., Offenhauser, N., Leithner, C., and Royl, G. (2010a). Pathophysiological interference with neurovascular coupling - when imaging based on hemoglobin might go blind. Front. Neuroenergetics 2:25 doi:10.3389/fnene.2010.00025

Lindauer, U., Leithner, C., Kaasch, H., Rohrer, B., Foddis, M., Fuchtemeier, M., Offenhauser, N., Steinbrink, J., Royl, G., Kohl-Bareis, M., and Dirnagl, U. (2010b). Neurovascular coupling in rat brain operates independent of hemoglobin deoxygenation. J. Cereb. Blood Flow Metab. 30, 757-768.

Lipton, P., and Whittingham, T. S. (1982). Reduced ATP concentration as a basis for synaptic transmission failure during hypoxia in the in vitro guinea-pig hippocampus. J. Physiol. (Lond.) 325, 51-65.

Lothman, E., Lamanna, J., Cordingley, G., Rosenthal, M., and Somjen, G. (1975). Responses of electrical potential, potassium levels, and oxidative metabolic activity of the cerebral neocortex of cats. Brain Res. 88, 15-36.

Masamoto, K., Kershaw, J., Ureshi, M., Takizawa, N., Kobayashi, H., Tanishita, K., and Kanno, I. (2007). Apparent diffusion time of oxygen from blood to tissue in rat cerebral cortex: implication for tissue oxygen dynamics during brain functions. J. Appl. Physiol. 103, 1352-1358.

Masamoto, K., Kurachi, T., Takizawa, N., Kobayashi, H., and Tanishita, K. (2004). Successive depth variations in microvascular distribution of rat somatosensory cortex. Brain Res. 995, 66-75.

Masamoto, K., Omura, T., Takizawa, N., Kobayashi, H., Katura, T., Maki, A., Kawaguchi, H., and Tanishita, K. (2003). Biphasic changes in tissue partial pressure of oxygen closely related to localized neural activity in guinea pig auditory cortex. J. Cereb. Blood Flow Metab. 23, 1075-1084.

Masamoto, K., Vazquez, A., Wang, P., and Kim, S. G. (2008). Trial-bytrial relationship between neural activity, oxygen consumption, and blood flow responses. Neuroimage 40, 442-450.

Mattson, M. P., and Liu, D. (2003). Mitochondrial potassium channels and uncoupling proteins in synaptic plasticity and neuronal cell death. Biochem. Biophys. Res. Commun. 304, 539-549.

Mayevsky, A., and Chance, B. (2007). Oxidation-reduction states of $\mathrm{NADH}$ in vivo: from animals to clinical use. Mitochondrion 7, 330-339.

Ndubuizu, O., and Lamanna, J. C. (2007). Brain tissue oxygen concentration measurements. Antioxid. Redox Signal. 9, 1207-1219.

Nicholls, D. G. (2003). Bioenergetics and transmitter release in the isolated nerve terminal. Neurochem. Res. 28, 1433-1441.

Pellerin, L. (2010). Food for thought: the importance of glucose and other energy substrates for sustaining 
brain function under varying levels of activity. Diabetes Metab. 36(Suppl. 3), S59-S63.

Pena, F., and Ramirez, J. M. (2005). Hypoxia-induced changes in neuronal network properties. $\mathrm{Mol}$. Neurobiol. 32, 251-283.

Pitler, T. A., and Landfield, P. W. (1987). Postsynaptic membrane shifts during frequency potentiation of the hippocampal EPSP. J. Neurophysiol. $58,866-882$.

Raichle, M. E., and Mintun, M. A. (2006). Brain work and brain imaging. Annu. Rev. Neurosci. 29, 449-476.

Rolleston, F. S., and Newsholme, E. A. (1967). Control of glycolysis in cerebral cortex slices. Biochem. J. 104, 524-533.

Rosenthal, M., and Jobsis, F. F. (1971). Intracellular redox changes in functioning cerebral cortex. II. Effects of direct cortical stimulation. J. Neurophysiol. 34, 750-762.

Schurr, A., and Payne, R. S. (2007). Lactate, not pyruvate, is neuronal aerobic glycolysis end product: an in vitro electrophysiological study. Neuroscience 147, 613-619.

Shuttleworth, C. W. (2010). Use of $\mathrm{NAD}(\mathrm{P}) \mathrm{H}$ and flavoprotein autofluorescence transients to probe neuron and astrocyte responses to synaptic activation. Neurochem. Int. 56, 379-386.

Simon, A. J., and Torbati, D. (1982). Effects of hyperbaric oxygen on heart, brain, and lung functions in rat. Undersea Biomed. Res. 9, 263-275.
Sullivan, P. G., Springer, J. E., Hall, E. D., and Scheff, S. W. (2004). Mitochondrial uncoupling as a therapeutic target following neuronal injury. J. Bioenerg. Biomembr. 36, 353-356.

Suzuki, A., Stern, S. A., Bozdagi, O., Huntley, G. W., Walker, R. H., Magistretti, P. J., and Alberini, C. M. (2011). Astrocyte-neuron lactate transport is required for long-term memory formation. Cell $144,810-823$.

Takano, T., Tian, G. F., Peng, W., Lou, N., Lovatt, D., Hansen, A. J., Kasischke, K. A., and Nedergaard, M. (2007). Cortical spreading depression causes and coincides with tissue hypoxia. Nat. Neurosci. 10, 754-762.

Tsai, Y. C., Chou, Y. C., Wu, A. B., Hu, C. M., Chen, C. Y., Chen, F. A., and Lee, J. A. (2006). Stereoselective effects of 3-hydroxybutyrate on glucose utilization of rat cardiomyocytes. Life Sci. 78, 1385-1391.

Turner, D. A., and Adamson, D. C. (2011). Neuronal-astrocyte metabolic interactions: understanding the transition into abnormal astrocytoma metabolism. J. Neuropathol. Exp. Neurol. 70, 167-176.

Turner, D. A., Foster, K. A., Galeffi, F., and Somjen, G. G. (2007). Differences in $\mathrm{O} 2$ availability resolve the apparent discrepancies in metabolic intrinsic optical signals in vivo and in vitro. Trends Neurosci. 30, 390-398.

Vazquez, A. L., Masamoto, K., Fukuda, M., and Kim, S. G. (2010).
Cerebral oxygen delivery and consumption during evoked neural activity. Front. Neuroenergetics 2:11. doi:10.3389/fnene.2010. 00011

Verweij, B. H., Amelink, G. J., and Muizelaar, J. P. (2007). Current concepts of cerebral oxygen transport and energy metabolism after severe traumatic brain injury. Prog. Brain Res. 161, 111-124.

Whittingham, T. S., Lust, W. D., Christakis, D. A., and Passonneau, J. V. (1984). Metabolic stability of hippocampal slice preparations during prolonged incubation. J. Neurochem. 43, 689-696.

Wilson, D. F., Erecinska, M., Drown, C., and Silver, I. A. (1979). The oxygen dependence of cellular energy metabolism. Arch. Biochem. Biophys. 195, 485-493.

Wyss, M. T., Jolivet, R., Buck, A., Magistretti, P. J., and Weber, B. (2011). In vivo evidence for lactate as a neuronal energy source. J. Neurosci. 31, 7477-7485.

Yamamoto, C., and Kurokawa, M. (1970). Synaptic potentials recorded in brain slices and their modification by changes in the level of tissue ATP. Exp. Brain Res. 10, 159-170.

Zhao, Y. T., Tekkok, S., and Krnjevic, K. (1997). 2-deoxy-D-glucoseinduced changes in membrane potential, input resistance, and excitatory postsynaptic potentials of CA1 hippocampal neurons. Can. J. Physiol. Pharmacol. 75 , 368-374.
Zilberter, Y., Zilberter, T., and Bregestovski, P. (2010). Neuronal activity in vitro and the in vivo reality: the role of energy homeostasis. Trends Pharmacol. Sci. 31, 394-401.

Zur Nedden, S., Hawley, S., Pentland, N., Hardie, D. G., Doney, A. S., and Frenguelli, B. G. (2011). Intracellular ATP influences synaptic plasticity in area CA1 of rat hippocampus via metabolism to adenosine and activity-dependent activation of adenosine Al receptors. J. Neurosci. 31, 6221-6234.

Conflict of Interest Statement: The authors declare that the research was conducted in the absence of any commercial or financial relationships that could be construed as a potential conflict of interest.

Received: 21 September 2011; accepted: 10 December 2011; published online: 29 December 2011.

Citation: Ivanov $A$ and Zilberter $Y$ (2011) Critical state of energy metabolism in brain slices: the principal role of oxygen delivery and energy substrates in shaping neuronal activity. Front. Neuroenerg. 3:9. doi: 10.3389/fnene.2011.00009

Copyright $\odot 2011$ Ivanov and Zilberter. This is an open-access article distributed under the terms of the Creative Commons Attribution Non Commercial License which permits non-commercial use, distribution, and reproduction in other forums, provided the original authors and source are credited. 